\title{
Emergency Cesarean Section in a Patient with Congenital Complete Heart Block under General Anesthesia: A Case Report
}

\author{
Pradeep Tiwari ${ }^{1}$, Shraddha S Mathkar ${ }^{2}$
}

\begin{abstract}
Congenital complete heart block in pregnancy is rare. Fetal distress permits no time for neuraxial blockade. Twenty-two years antenatal clinic diagnosed atrioventricular dissociation and complete heart block at 6 months of pregnancy, presented with fetal distress at 36 weeks. General anesthesia was given with transcutaneous pacemaker standby. Healthy baby was delivered. One episode of bradycardia occurred which responded to Inj atropine $0.6 \mathrm{mg}$ IV however blood pressure was stable. We managed lower segment cesarean section (LSCS) in complete hearth block with fetal distress uneventfully with general anesthesia.

Keywords: Congenital complete heart block, Emergency LSCS, Transvenous pacing.

Research and Innovation in Anesthesia (2019): 10.5005/jp-journals-10049-0057
\end{abstract}

\section{INTRODUCTION}

Incidence of congenital complete heart block (CCHB) is $1: 22,000$ live births. ${ }^{1}$ Parturient with congenital heart block may be asymptomatic but can present with a sudden vascular collapse, especially during labour. Few patients with congenital heart block may have sudden cardiac death (SCD), for which there are no predictors. ${ }^{2}$ It is a team work of anesthesiologist, obstetrician, and cardiologist to manage CCHB with pregnancy in fetal distress coming for emergency lower segment cesarean section (LSCS) done under general anesthesia.

\section{Case Description}

A 22-year-old primigravida attended regular ANC opd with a low heart rate at 6 months of pregnancy. Cardiology evaluation was done. The patient was asymptomatic with a pulse rate of 44/minute, BP-120/70 mm Hg, RS—normal, CVS—S1, S2 normal, NO murmur. ECG showed a complete atrioventricular dissociation with a ventricular rate of 42 /minute, $2 \mathrm{D}$ echo-no structural abnormality, $\mathrm{EF}-55 \%$, no regional wall motion abnormality, and no diastolic dysfunction. Holter monitoring showed a heart rate of 40-60/minute, with no complex ventricular ectopic beats. Hypothyroidism and systemic lupus erythematosus (SLE) were ruled out. The patient was advised regular followup and institutional delivery. The cardiologist was informed during delivery for pacemaker standby.

At 36 weeks of pregnancy, the patient was admitted for elective section. On admission, general condition was stable; pulse rate was $46 /$ minute, respiratory rate was $20 /$ minute, and blood pressure (BP) was $110 / 70 \mathrm{~mm} \mathrm{Hg}$. ECG showed a complete atrioventricular dissociation with a ventricular rate of 42 /minute. Fetal heart sounds were 145/minute. All her routine investigations were within normal limits. In the evening of after admission, there was meconium stained liquor and fetal drops up to 90 /minute. The patient was immediately wheeled in for an emergency cesarean section under ASA IIE.

High-risk consent and NPO confirmed that all routine monitors were attached. General anesthesia was mandatory in view of fetal distress. Trancutaneous pacing, inj isoprenaline in infusion pump were kept ready. The cardiologist was informed about the case.
1,2Department of Anaesthesiology, King Edward Memorial Hospital and Seth Gordhandas Sunderdas Medical College, Mumbai, Maharashtra, India

Corresponding Author: Pradeep Tiwari, Department of Anaesthesiology, King Edward Memorial Hospital and Seth Gordhandas Sunderdas Medical College, Mumbai, Maharashtra, India, Phone: +91 7666112804, e-mail: coolpradeep.15@gmail.com

How to cite this article: Tiwari P, Mathkar SS. Emergency Cesarean Section in a Patient with Congenital Complete Heart Block under General Anesthesia: A Case Report. Res Inno in Anesth 2019;4(1): 9-10.

Source of support: Nil

Conflict of interest: None

Inj ranitidine $50 \mathrm{mg}$, inj ondansetrone $4 \mathrm{mg}$ was administered. 4 vital capacity breaths were given to patient prior to induction while patient was painted and draped by the surgeons. Induction was done with titrated doses of inj thiopentone $125 \mathrm{mg}+$ inj ketamine $45 \mathrm{mg}$, inj rocuronium $1 \mathrm{mg} / \mathrm{kg}$ given with Sellicks maneuver. Airway was secured with 7 number portex cuffed endotracheal tube. After confirming air entry, the tube was fixed and surgery started. A baby was delivered in 5 minutes. Inj pentazocine $30 \mathrm{mg}+$ inj midazolam $1 \mathrm{mg}$ were given intravenously and inj pitocin $20 \mathrm{IU}$ was administerd through an intravenous infusion. Hemodynamics were monitored throughout the procedure. Heart rate varied from $40 /$ minute to $54 /$ minute. There was a drop in heart rate on one occasion to 40 /minute. Inj atropine $0.6 \mathrm{mg}$ was given, and within a minute it came up to $60 /$ minute; however, there was no drop in blood pressure. Inj neostigmine $2.5 \mathrm{mg}+$ inj atropine $1.2 \mathrm{mg}$ slowly titrated was given for reversal of neuromuscular blockade. The patient was extubated, heart rate dropped to 40 /minute after reversal, but blood pressure was normal. She was observed in recovery for 1 hour. Heart rate was maintained at 40-50/minute and blood pressure was within normal limits. After consultation with the cardiologist, the patient was shifted to the ward. 


\section{Discussion}

Congenital complete heart block is a rare condition with an incidence of 1:22,000. ${ }^{1}$ Many patients are asymptomatic for routine lifestyle. It is usually due to anatomical discontinuity between AV node and the bundle of his. These patients develop a junctional escape rhythm at around 40-45/minute. Our patient presented with narrow QRS complex rhythm with a heart rate of 45-50 beats/minute.

The AV node responds to sympathomimetic stimulation, stress, and atropine test. Stress test can be done in CCHB patients to see the response but was avoided as the patient was 6 months pregnant. Atropine test causes fetal tachycardia; so it was avoided. Tachycardia and low vascular resistance helps placental perfusion to nourish the baby in a normal physiologic changes seen in pregnancy. In $\mathrm{CCHB}$, pregnancy is well tolerated by lower vascular resistance. Patients who are symptomatic with hypotension and syncope need a permanent pacemaker prior. Recommendation for pacemaker insertion is congenital AV block in adults are ${ }^{3}$

Class I-congenital third-degree AV block with a wide QRS escape rhythm, complex ventricular ectopy, or ventricular dysfunction.

Class IIb-congenital third-degree AV block beyond the first year of life with an average heart rate less than $50 \mathrm{bpm}$, abrupt pauses in ventricular rate that are 2 or 3 times the basic cycle length, or associated with symptoms owing to chronotropic incompetence.

The patient was asymptomatic in our case; so a permanent pacemaker was not inserted. Prophylactic pacemaker insertion is not preferred these days. ${ }^{4-6}$ Transvenous pacemaker was kept standby, as it was an emergency section in view of fetal distress. Transcutaneous pacing is the treatment of choice for any symptomatic patient. ${ }^{7,8}$ It is easy, noninvasive, and a time tide over procedure that is done in minutes and do not need a trained personel. Disadvantage include loss of capture. Isoprenaline is a chemical pacemaker, should only be used as a temporary measure until more definitive and less risky treatments (e.g., transvenous pacing) can be arranged.

Many case reports were CCHB are done in epidural, spinal, and combined spinal epidural. Modi et al. report successful anesthetic management using epidural blockade for elective LSCS in a parturient with complete heart block. ${ }^{9}$ Umesh et al. reported a case of congenital complete heart block and spinal anesthesia for cesarean section. ${ }^{10}$

Neuraxial blockade causes sympathetic blockade, which demands an increase in heart rate; so it becomes mandatory to accelerate the heart rate using a pacemaker. The heart rate required to meet the cardiac output is unpredictable. Fixed pacemaker setting in VVI mode may not meet the need of inotropy at the time of labour. Bupivacaine commonly used for subarachnoid block is known to interact with the conducting system of the heart.
General anesthesia was preferred in view of fetal distress in our patient. Inj thiopentone and inj ketamine titrated were used for induction slowly with flush solution as the circulation time is slow. These drugs antagonize each other in terms of heart rate. Inj rocuronium $1.2 \mathrm{mg} / \mathrm{kg}$ was given and tube was secured. Drugs such as succinylcholine, fentanyl, neostigmine, and vecuronium are known to cause bradycardia and asystole. Inj propofol and inhalational agents are known to aggravate conduction blocks. Under anesthesia, chances of hypotension, bradycardia, even cardiac arrest are the disastrous complications.

Titrated doses of general anesthestics help maintain the hemodynamics better. Inj pentazocine causes a relative rise in heart rate when compared to Fentanyl. Our patient probably had a block at the level of A-V node as she was hemodynamically stable and there was an increase in heart rate after inj atropine $(1.2 \mathrm{mg}$ ). We successfully managed CCHB with fetal distress under general anesthesia with transcutaneous pacing, Isoprenaline infusion was standby.

\section{Conclusion}

A multidisciplinary approach along with transcutanous pacing standby avoids invasive transvenous pacing in patients with congenital heart block for emergency LSCS.

\section{References}

1. Kertesz NJ, Freidman AL. Congenital complete atrioventricular block. Texas Heart Institute Journal 1997;24(4):301-307.

2. Perloff JK. Isolated congenital heart block. In: The clinical recognition of congenital heart disease. 5th ed., Philadelphia: Saunders; 2012. pp. 46-48.

3. ACC/AHA/HRS. Guidelines for device based therapy of cardiac rhythm abnormalities; 2008, ch. 2.5. pp. 367-368.

4. Dalvi BV, Chaudhuri A, Kulkarni HL, et al. Therapeutic guidelines for congenital complete heart block presenting in pregnancy. Obstet Gynecol 1992;79:802-404.

5. Kenmure AC, Cameron AJ. Congenital complete heart block in pregnancy. Br Heart J 1976;29:911-913.

6. Csontos CS, Bogar L, Melczer L. Temporary pacemakers for non-cardiac surgery. Eur J Anaesthesiol 2003;20:575-578. DOI: 10.1097/00003643-200307000-00014.

7. Hidaka N, Chiba Y, Kurita T, et al. Is intrapartum temporary pacing required for women with complete atrioventricular block? An analysis of seven cases. BJOG 2006;113(5):605-607. DOI: 10.1111/j.14710528.2006.00888.x.

8. Gambling DR, Joanne-Douglas M, McKay RSF. Obstetric Anesthesia and Uncommon Disorders; 2008. p. 33.

9. Modi MP, Butala B, Shah VR. Anesthesia management of unusual case of complete heart block for LSCS. Indian J Anaesth 2006;50(1): 43-44.

10. Umesh Kumar A, Sripriya R, Parthasarathy S, et al. Congenital complete heart block and spinal anesthesia for caesarean section. Indian J Anaesth 2012;56(1):72-74. DOI: 10.4103/0019-5049. 93350. 